\title{
Specific heat of nano-ferrites modified composites
}

\author{
Cristian Muntenita ${ }^{1}$, Claudia Ungureanu ${ }^{1}$, Vasile Bria ${ }^{1}$, and Iulia Graur ${ }^{1,2, *}$ \\ 1"Dunarea de Jos" University of Galati, Research and Development Centre for Thermoset Matrix \\ Composites, Galati, Romania \\ ${ }^{2}$ Diagnose and Measurement Group, Galati, Romania
}

\begin{abstract}
The specific heat of nano-ferrites modified composites was studied using differential scanning calorimeter (DSC) method in the temperature range of 30 to $150^{\circ} \mathrm{C}$. Initially, nano-ferrites were introduced in epoxy systems in order to improve the electromagnetic properties of formed materials. Together with the changes in electromagnetic properties some modifications occur regarding thermal and mechanical properties. The materials were formed by placing $5 \mathrm{~g}$ or $10 \mathrm{~g}$ of ferrite into $250 \mathrm{~g}$ polymer matrix leading to a very low weight ratio of modifying agent. At so low ratios the effect of ferrite presence should be insignificant according to mixing rule. Anyway there is possible to appear some chelation reaction with effects on thermal properties of materials. Three types of epoxy resins had been used as matrix and barium ferrite and strontium ferrite as modifying agents. The thermal analysis was developed on two heatingcooling cycles and the specific heat was evaluated for each segment of the cycle analysis.
\end{abstract}

\section{Introduction}

Composite materials are the first materials with internal structural layout conceived by man, both through of their molecular structure and through preferential directions, thus giving them increased resistance, superior to those of their constituents. The use of polymeric materials represent a number of advantages compared to traditional materials [1-2]. The properties of these materials are: low energy consumption during production, minimize the impact on the environment, corrosion resistance, tensile strength, wear resistance, resistance to high temperatures, the hardness of the surface, dimensional stability, resistance to the environment, the thermal conductivity or thermal insulation, electrical conductivity, and large usage spectrum: medicine, by making dental implants and bone, aerospace industry by developing various components of the vehicle, automotive industry by developing various structural components, the sports industry through the development of various vehicles: bicycles, boats and sport equipment, energy industry through by applications in the field of wind energy ( the wind turbines whose blades are made of composite) [3-5].

The developing of the composite materials was based both on economic and technical considerations. Among them we can remember: the need to make materials with special

\footnotetext{
*Corresponding author: iulia.graur@ugal.ro
} 
properties, impossible to attain by traditional materials, the need to increase the safety and reliability in operation, the need to reduce the consumption of materials deficient, expensive or precious, with the possibility to reduce the time for the technological manufacturing and man-hours and last but not least the extend of the lifetime of the materials [6-7]. To get superior properties of polymers one usual way is to modify it by placing another phase, for instance a nano-sized one, into the polymer volume [8]. Ferrites remain the best magnetic material and cannot be replaced by any other magnetic elements because they are inexpensive, more stable and have a wide range of technological applications in transformer cores, high quality filters, radio wave circuits and operating devices [9-10].

According to the literature, the formation of polymeric composites, does not allow discussing interest issues from a single point of view, more than that, polymers properties can be controlled by synthesis and adapted to applications. Starting from the idea that the composite materials have good mechanical properties and affordable forming techniques, these are increasingly used in elements repairing or even replace them. Here we can mention the current trend of replacing traditional structures with composite materials, which have a higher life expectancy, high corrosion resistance, good elastic properties than traditional materials (pipelines for transportation - gas, water) [11-13].

Specific heat is the quantity of heat required to raise the temperature of a unit mass of a substance one degree under specified conditions. This property is measured in a calorimeter. In practice, the specific heat at constant pressure or enthalpy, $\mathrm{Cp}$, is the measured quantity, with values reported in $\mathrm{J} /(\mathrm{kgK})$ in SI units. The standard test method for measuring the specific heat of polymer matrix composites is ASTM E1269-95, and is based on Differential Scanning Calorimetry (DSC). The temperature range can be extended depending upon the instrumentation and specimen holders used. A quantitative measurement of energy imparted to a test specimen as a function of temperature must be obtained to determine specific heat. Thus, the instrument used for these measurements must be calibrated in both the heat flow and temperature modes. Application of the DSC test method to polymer matrix composites may also encounter difficulties due to specimen mass loss from either moisture evolution or material decomposition, but this problem can be overcome by taking proper precautions [14].

This work goal is to analysis the composite materials modified with nano-ferrites (barium and strontium ferrites) with matrix made from three different epoxy resins, in particular specific heat.

\section{Experimental procedure}

Three epoxy systems were chosen namely: Epiphen RE4020-DE 4020 (Bostik), (C) Epoxy Resin C (R\&G Gmbh Waldenbuch), and (HT) Epoxy Resin HT-2 (R\&G Gmbh Waldenbuch). Ferrites used in this study are commercially available ferrite: Strontium ferrite $\left(\mathrm{SrFe}_{12} \mathrm{O}_{19}\right)$ and barium ferrite $\left(\mathrm{BaFe}_{12} \mathrm{O}_{19}\right)$. All these systems were modified by mixing the main component of the respective epoxy system (the resin) with $5 \mathrm{~g}$ of ferrite and $10 \mathrm{~g}$ of both ferrites [15].

The codifications for the materials used in this study are: $\mathrm{C} 1, \mathrm{E} 1, \mathrm{H} 1$ - epoxy resin with $5 \mathrm{~g}$ barium ferrite; C2, E2, H2 - epoxy resin with $5 \mathrm{~g}$ strontium ferrite; C3, E3, H3 - epoxy resin with $5 \mathrm{~g}$ strontium and $5 \mathrm{~g}$ barium ferrite; $\mathrm{C}, \mathrm{E}$ and $\mathrm{H}$ - unchanged resins.

In order to determine the specific heat a differential scanning calorimeter DSC Mettler Toledo was used. This device is equipped with a sensor that is designed to control the atmospheric conditions inside the cell and ensure proper symmetry between the final sample and the reference sample. The DSC operation and data acquiring are possible with the two elements of DSC Mettler Toledo: measuring chamber (cell) and STARe application for data acquisition and evaluation. The specific heat was determined from the heat absorption curve and / or the released heat for each type of material. Test method is defined by two cycles as 
follows: 30 minutes $30^{\circ} \mathrm{C}$ isotherm heating from $30^{\circ} \mathrm{C}$ to $150^{\circ} \mathrm{C}$ with a ratio of $10 \mathrm{~K}$-min, $150^{\circ} \mathrm{C}$ isotherm and cooling from $150^{\circ} \mathrm{C}$ to $30^{\circ} \mathrm{C}$ with a ratio of $10 \mathrm{~K} / \mathrm{min}$ and the cycle is repeated.

Both heating and cooling DSC curves can provide information on the nature of tested material. When talking about polymeric materials, the curves provide information on the glass transition temperature and melting temperature.

\section{Results and discussion}

Regarding specific heat values of studied materials, it may be noted that measured results shows several values lower than expected. This is due to chemical interactions which lead to formation of a new polymer. Thermal analysis were carried out in different temperature ranges from $30^{\circ} \mathrm{C}$ to $150^{\circ} \mathrm{C}$. Interest temperature interval in this study is $70-120^{\circ} \mathrm{C}$. For these values comparative charts were made (Figure 1-3). In the case of $\mathrm{C}$ modified epoxy resin materials, specific heat values shows a significant increase compared with unchanged epoxy matrix materials. The highest specific heat values were obtained for $\mathrm{C}$ modified epoxy resin materials. This is caused by the type of modifying agent (baric ferrite) used alone or in combination with strontium ferrite for $\mathrm{C} 1$ and $\mathrm{C} 3$ materials. It can be seen that the modifying agent has a beneficial effect on the materials thermal properties (Figure 1).

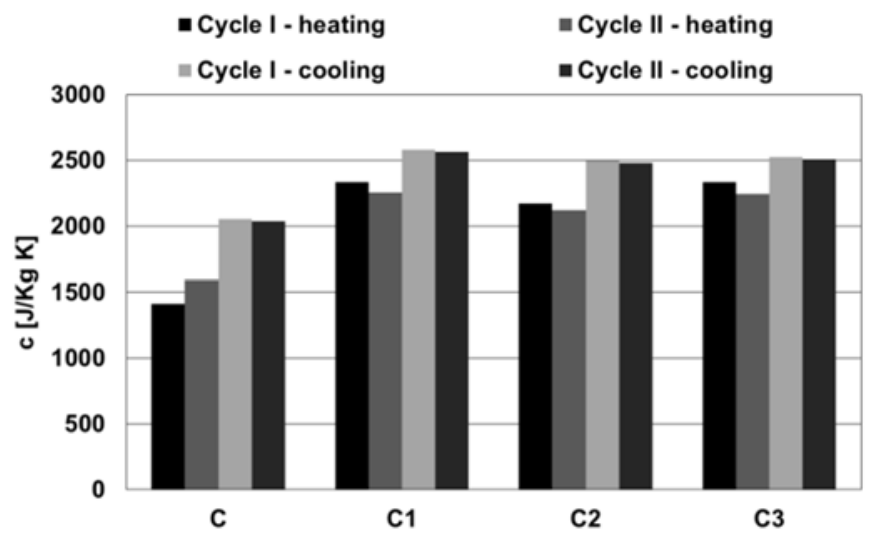

Fig.1. Specific heat values of $\mathrm{C}$ modified epoxy resin materials $\left(70-120^{\circ} \mathrm{C}\right.$ temperature interval).

In the case E type materials the same working protocol was kept, in order to determine the heat absorption. This test, like the others, has aimed to highlighting the thermal properties (specific heat) for the modified materials in comparison with unchanged epoxy resin. In the case of $\mathrm{E}$ modified epoxy resin materials it is noted that, when heated, the amount of modifying agent and also the combination of modifiers and matrix is a good one. Thus, can be noticed increased specific heat values for E3 material (Figure 2). For cooling there are not significant variations in specific heat values. Under the tested conditions it can be seen that baric ferrite improves the thermal properties of $\mathrm{E}$ type materials and $\mathrm{C}$ type materials. 


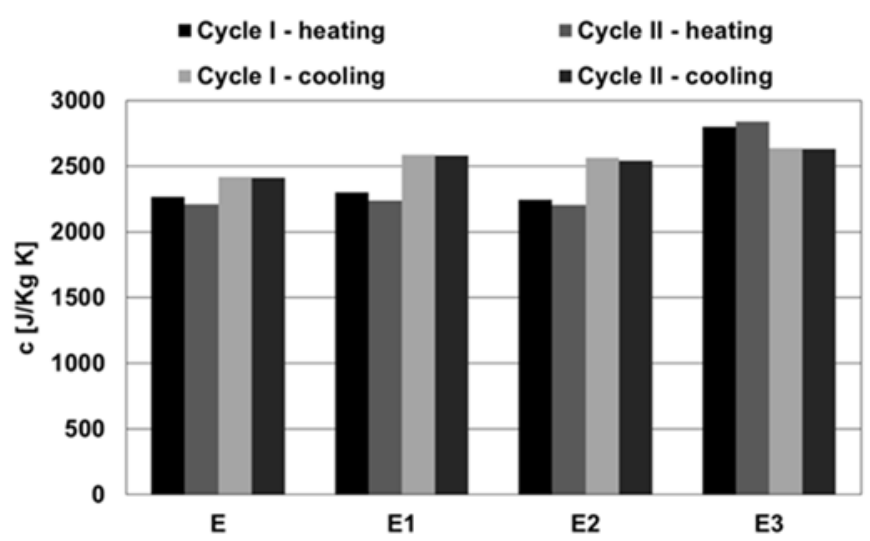

Fig.2. Specific heat values of E modified epoxy resin materials $\left(70-120^{\circ} \mathrm{C}\right.$ temperature interval).

HT type materials have shown variations in the specific heat values depending on the used modifying agent. Figure 3 shows, in graphical form, the specific heat values following the two cycles of heating and cooling. We can observe the behavior of the modified materials compared with epoxy resin and also the modifying agent behavior. The highest values of specific heat were recorded for HT modified epoxy resin materials (with baric ferrite) (Figure 3 ). For HT3 material specific heat values average in the studied temperature interval can be influenced by the amount of modifying agent in the polymer matrix. For cooling there are not significant variations in specific heat values for HT modified epoxy resin materials.

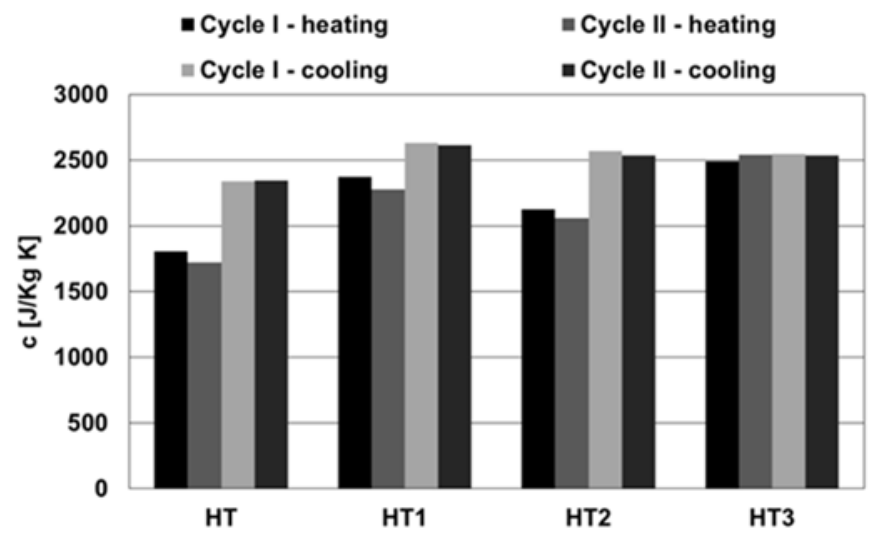

Fig.3. Specific heat values of HT modified epoxy resin materials $\left(70-120^{\circ} \mathrm{C}\right.$ temperature interval).

Before and after specific heat values tests, the samples were weighed to determine the mass loss (Figure 4). This loss is influenced by the presence of residual water and other volatile compound from the polymer. Generally the largest mass loss values were recorded for $\mathrm{C}$ modified epoxy resin materials while the lowest were recorded for $\mathrm{E}$ modified epoxy resin materials. 


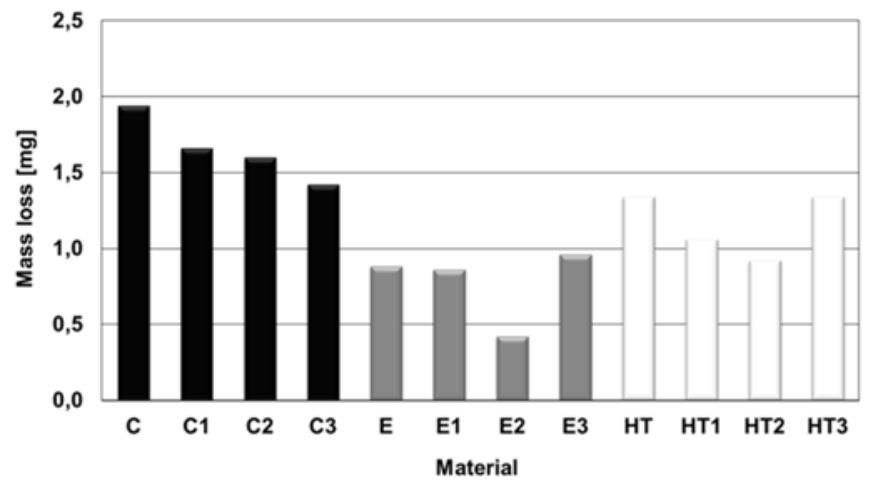

Fig.4. Mass loss of epoxy matrix materials.

Strontium ferrite produced significant variations in the mass loss depending on the type of used epoxy system. Thus the highest value is recorded for materials for E type materials and the lower for HT type materials. The combination of strontium ferrite and baric ferrite led to lower mass loss in the case of C type materials and higher in the case of HT type materials compared to homogeneous systems.

\section{Conclusions}

In the comparative analysis on heating cycles, different behavior and higher values of specific heat is due to chemical interaction between epoxy matrix and modifying agent. Also, the interaction between the two agents resulted in an improvement of the thermal properties of modified materials. Modified materials specific heat values are generally higher compared to unmodified epoxy systems. Better thermal properties were observed for those materials where both modifying agents were used. The mass loss is visible for all materials, regardless of matrix type or amount of modifying agent. Mechanisms that could explain the behavior of nano-ferrite modified materials can be explained by the nature and by the used amount of modifying agent.

The present study is part of research activity under the Project POSCCE 12P01.024/CD111. The research activity was developed at Research and Development Centre for Thermoset Matrix Composites, "Dunarea de Jos" University of Galati.

\section{References}

1. D. Craver Clara, C. E. Jr. Carraher, J. Appl. Polym. Sci., in Introduction to polymer science and technology, (2000)

2. A. Curt, NM Epoxy Handbook, Nils Malmgren AB, (2004)

3. J. P. Pascault, R. J. J. Williams, Epoxy Polym. , New Materials and Inovations, (2010)

4. L.V. Mc Adams, J.A. Gannon, Encyclopedia of polymer science and engineering, 6, (1986)

5. P.D. Wallace, Thermosetting resins, Borden Chemical, (2011)

6. C. Muntenita, C. Ungureanu, V. Bria, I. Graur, Bending Behaviour of Nano-ferrites Modified Epoxy Resins, ICMSAV2016\& COMAT2016, 6, (2016)

7. C. Muntenita, V. Bria, C. Eni, A. Cîrciumaru, I. Graur, Physical characterization of nano-ferrites modified epoxy resins, Mat. Plastice, 53, 3, (2016) 
8. J.C.J. Bart, Additives in Polymers. Industrial Analysis and Applications, 1, (2005)

9. M. Delgado, A. Lazaro, J. Mazo, B. Zalba, Review on phase change material emulsion and microencapsulated phase change materiel slurries: materials, heat transfer studies and applications, Renew.Sustain.EnergyRev., 16, (2012)

10. B. A. Strong, Fundamentals of Composites Manufacturing: Materials, Methods, and Applications, 2, SME, (2008)

11. A. Fallahi, L. Rajabi, F.A. Taromi, DSC Analysis of Thermosetting Polyimides Based on Three Bismaleimide Resin Eutectic Mixtures, Iranian Polymer Journal, 20, (2011)

12. J. Le Blanc, Filled Polymers. Science and Industrial Applications, (2010)

13. C. Barreneche, A. Solé, L. Miró, I. Martorell, A. InèsFernández, L.F. Cabeza, Study on differential scanning calorimetry analysis with two operation modes and organic and inorganic phase change material (PCM), Thermochim.Acta., 553, (2013)

14. Composite Materials Handbook, Polymer matrix composites guidelines for characterization of structural materials, 1, (2002)

15. C. Muntenita, I. Graur, A. Boboc, C. Ungureanu, V. Bria, Compressive Behavior of Nanoferite Modified Epoxy Resins, The Romanian Review Precision Mechanics Optics \& Mechatronics, 50, (2016) 